\title{
Vanadium distribution, lipid peroxidation and oxidative stress markers upon decavanadate in vivo administration
}

\author{
S.S. Soares ${ }^{a, b}$, H. Martins ${ }^{\text {c }}$, R.O. Duarte ${ }^{\text {d }}$, J.J.G. Moura ${ }^{\text {c }}$, J. Coucelo ${ }^{\text {a,b }}{ }^{\text {, }}$ \\ C. Gutiérrez-Merino ${ }^{\mathrm{e}}$, M. Aureliano ${ }^{\mathrm{a}, \mathrm{c}, *}$ \\ a CCMAR, Universidade do Algarve, Campus de Gambelas, 8005-139 Faro, Portugal \\ ${ }^{\mathrm{b}}$ Faculdade de Ciências do Mar e do Ambiente, Universidade do Algarve, Campus de Gambelas, 8005-139 Faro, Portugal \\ ${ }^{\mathrm{c}}$ Departamento de Quimica e Bioquímica, Faculdade de Ciências e Tecnologia, Universidade do Algarve, Campus de Gambelas, 8005-139 Faro, Portugal \\ ${ }^{\mathrm{d}}$ REQUIMTE, Departamento de Química, Faculdade de Ciências e Tecnologia, Universidade Nova de Lisboa, Monte da Caparica, Portugal \\ e Departamento de Bioquímica y Biología Molecular, Facultad de Ciencias, Universidad de Extremadura, Av. Elvas s/n, 06071 Badajoz, Spain
}

Received 29 June 2006; received in revised form 17 August 2006; accepted 21 August 2006

Available online 30 August 2006

\begin{abstract}
The contribution of decameric vanadate species to vanadate toxic effects in cardiac muscle was studied following an intravenous administration of a decavanadate solution ( $1 \mathrm{mM}$ total vanadium) in Sparus aurata. Although decameric vanadate is unstable in the assay medium, it decomposes with a half-life time of 16 allowing studying its effects not only in vitro but also in vivo. After 1, 6 and $12 \mathrm{~h}$ upon decavanadate administration the increase of vanadium in blood plasma, red blood cells and in cardiac mitochondria and cytosol is not affected in comparison to the administration of a metavanadate solution containing labile oxovanadates. Cardiac tissue lipid peroxidation increases up to $20 \%, 1,6$ and $12 \mathrm{~h}$ after metavanadate administration, whilst for decavanadate no effects were observed except $1 \mathrm{~h}$ after treatment $(+20 \%)$. Metavanadate administration clearly differs from decavanadate by enhancing, $12 \mathrm{~h}$ after exposure, mitochondrial superoxide dismutase (SOD) activity $(+115 \%)$ and not affecting catalase (CAT) activity whereas decavanadate increases SOD activity by $20 \%$ and decreases $(-55 \%)$ mitochondrial CAT activity. At early times of exposure, 1 and $6 \mathrm{~h}$, the only effect observed upon decavanadate administration was the increase by $20 \%$ of SOD activity. In conclusion, decavanadate has a different response pattern of lipid peroxidation and oxidative stress markers, in spite of the same vanadium distribution in cardiac cells observed after decavanadate and metavanadate administration. It is suggested that once formed decameric vanadate species has a different reactivity than vanadate, thus, pointing out that the differential contribution of vanadium oligomers should be taken into account to rationalize in vivo vanadate toxicity.
\end{abstract}

(C) 2006 Elsevier Inc. All rights reserved.

Keywords: Decavanadate; Vanadate; Cardiac tissue; Mitochondria; Oxidative stress

\section{Introduction}

Several biological studies associate vanadium with the ability to produce reactive oxygen species (ROS) resulting

\footnotetext{
* Corresponding author. Address: Departamento de Química e Bioquímica, Faculdade de Ciências e Tecnologia, Universidade do Algarve, Campus de Gambelas, 8005-139 Faro, Portugal. Tel.: +351 289800 900x7643; fax: +351 289819403 .

E-mail address: maalves@ualg.pt (M. Aureliano).
}

in antioxidant enzymes alterations and leading to lipid peroxidation [1-8]. The involvement of toxic metals in cardiac oxidative damage suggests that this organ shows a great vulnerability to metal intoxication [9-12]. Notwithstanding, and despite the magnitude of the knowledge so far accumulated, the biochemical basis for the observed in vivo oxidative effects of vanadium in cardiac tissue are still poorly defined.

Most of toxicological vanadate studies in biology do not take into consideration the contribution of vanadate 
oligomers, in spite that at the concentrations normally used the vanadate solutions also contains several vanadate oligomers besides the monomeric vanadate (V1), such as dimeric (V2) and tetrameric (V4) vanadate species. Furthermore, decameric vanadate species (V10), which are formed upon medium acidification, are well known to affect the activity of several enzymes [13-15]. It has been suggested that V10 decomposition is slow enough to allow studying its effects in biochemical systems [16,17], not only in vitro but also in vivo [16-21]. More recently, it was described that V10 can be stabilized upon interaction with cytoskeleton and membrane proteins [22]. Therefore, we cannot exclude the hypothesis that V10 may also occur at physiological conditions for long enough to induce different biological effects in comparison to metavanadate. If V10 would occur at physiological conditions, does it induce specific effects in vivo? Are these effects different from the ones promoted by metavanadate? Does V10 also contribute to the toxicity induced by vanadate? Once formed in vivo, does decavanadate prevent the effects induced by metavanadate?

To our knowledge, very few in vivo studies with V10 have been published so far. Since 1999, our group has performed in vivo administration of decavanadate in order to understand the contribution of V10 to the toxic effects of vanadate [16-21]. A metavanadate solution not containing V10 was also administered as a comparison group of study, besides a placebo group. Until now, following in vivo administration of V10, several parameters were analysed such us: subcellular vanadium distribution; lipid peroxidation; antioxidants enzymes activities besides several oxidative stress markers. Among the different experimental conditions described, it was included different: mode of V10 administration (intraperitoneal, i.p. versus intravenous, i.v.); animal species (Halobatrachus didactylus and Sparus aurata); vanadate concentration $(5 \mathrm{mM})$; tissues (cardiac, hepatic, renal, blood); subcellular fractions (cytosol, mitochondria, red blood cells, blood plasma); exposure time (12 and $24 \mathrm{~h}, 2$ and 7 days). Therefore, besides the interest of piscine models to oxidative stress studies, being more sensitive to heavy metals toxicity than mammals, it has been shown to be very useful to study decavanadate toxicity, since at the fish physiological temperature decameric vanadate species is stable enough to induce different effects than vanadate itself.

In the present work, we report the most relevant findings both with mitochondrial and cytosolic cardiac subcellular fractions following V10 in vivo administration at early exposure times (1, 6 and $12 \mathrm{~h}$ ) and for sublethal concentration ( $1 \mathrm{mM}$ total vanadium) of two vanadate solutions (decavanadate and metavanadate) intravenously injected in Sparus aurata (gilthead seabream). For early times of exposure and lower vanadate concentration, in vivo V10 administration was found to induce a different pattern of ROS production and lipid peroxidation and different changes on superoxide dismutase and catalase activities than metavanadate.

\section{Material and methods}

\subsection{Vanadate solutions}

Metavanadate stock solution $(50 \mathrm{mM}, \mathrm{pH}$ 6.7) was prepared from ammonium metavanadate purchased from Riedel-de-Haën. Decavanadate stock solution was obtained by adjusting the $\mathrm{pH}$ of the former solution to 4.0 [23]. Decavanadate stock solutions were always adjusted to $\mathrm{pH}$ about 7.0 immediately before using; being both deca and metavanadate solutions diluted to the final concentration $(1 \mathrm{mM})$ in physiological solution $(0.9 \% \mathrm{NaCl})$ and kept on ice before use. Whereas the metavanadate solution is stable, an estimate half-life time of $16 \mathrm{~h}$ was estimated for decameric species that partially deoligomerizes in the injection medium $(0.9 \% \mathrm{NaCl})$, in agreement with our previous reports $[16,17]$.

\subsection{NMR measurements}

The vanadate oligomers present in decavanadate and metavanadate solutions used on the study of vanadium in vivo effects on oxidative stress responses were measured by ${ }^{51} \mathrm{~V}$ Nuclear Magnetic Resonance spectroscopy in a Bruker AM-400 spectrometer at $105.2 \mathrm{MHz}$ equipped with a $5 \mathrm{~mm}$ multinuclear inverse probe, by using a $90^{\circ}$ pulse Fourier transform technique. Spectra were acquired at room temperature using $0.5 \mathrm{ml}$ of vanadate samples in the injection medium $(0.9 \% \mathrm{NaCl})$ or in the presence of $5 \%$ blood plasma, containing at least $10 \% \mathrm{D}_{2} \mathrm{O}$, under the following conditions: spectral width $45455 \mathrm{~Hz}$, accumulation time $0.05 \mathrm{~s}$ and relaxation delay $0.01 \mathrm{~s}$. Chemical shift values are given with reference to $\mathrm{VOCl}_{3}(0 \mathrm{ppm})$ as a standard. The relative areas of the several free and bound vanadate resonances were integrated and the line widths were obtained after subtracting the value $(20 \mathrm{~Hz})$ used in line broadening. The concentration of vanadate oligomers $V_{x}$ was calculated from the fractions of the total integrated areas observed in the recorded spectra as described (Eq. (1)). The symbol $A$ corresponds to the area measured for the $x$ vanadate species with the $n$ aggregation number (number of vanadium atoms), $A_{\mathrm{t}}$ the sum of measured areas and $\left[V_{\mathrm{t}}\right]$ corresponds to total vanadate concentration.

$\left[V_{x}\right]=\frac{A_{x}}{A_{\mathrm{t}}} \times \frac{\left[V_{\mathrm{t}}\right]}{n}$.

The calculated concentrations of vanadate oligomers were reproducible within $2-4 \%$. For quantitative measurements all spectra parameters were kept constant.

\subsection{Animals and treatments: in vivo studies}

Gilthead seabream (Sparus aurata), weighing 400-600 g were obtained from a local fish-farm at the Algarve region, south coast of Portugal. Fish were maintained in $450 \mathrm{~L}$ tanks, in aerated and recirculating seawater, under controlled conditions $\left(20^{\circ} \mathrm{C}, 35 \%\right.$ and exposed to natural 
Table 1

Reactive oxygen species (ROS), superoxide dismutase (SOD), catalase (CAT) and lipid peroxides (thiobarbituric reactive species - TBARS) basal/control values in cardiac tissue of Sparus aurata

\begin{tabular}{ll}
\hline & Basal/control values \\
\hline $\begin{array}{l}\text { Mitochondrial overall ROS } \\
\text { production }\end{array}$ & $384 \pm 140 \mathrm{a} . \mathrm{u} . / \mathrm{min} / \mathrm{mg}$ protein \\
Mitochondrial SOD activity & $20091 \pm 6951 \mathrm{U} / \mathrm{mg}$ protein \\
Mitochondrial CAT activity & $1.63 \pm 0.51 \mathrm{nmol} / \mathrm{min} /$ \\
& $\mathrm{mg}$ protein \\
Lipid peroxidation & $3.02 \pm 0.51 \mu \mathrm{M} \mathrm{TBARS} / \mathrm{g}$ tissue \\
\hline
\end{tabular}

Values are presented as means $\pm \mathrm{SD}(n=3)$.

day/night cycles) for 2 weeks prior to experimentation. During adaptation to laboratory conditions, fish were daily fed ad libitum with commercial fish pellets and were starved for 2 days, before sacrificed with anaesthetic overdosage of 2-fenoxiethanol (bath). For in vivo assays: 54 individuals were divided in three groups (Placebo, Deca and Meta groups) and treated with an intravenous (i.v.) injection of $1 \mathrm{ml} / \mathrm{kg}$ of $0.9 \% \mathrm{NaCl}$ or $1 \mathrm{mM}$ vanadium, as decavanadate or metavanadate, respectively; sub-groups of six individuals were sacrificed 1,6 and $12 \mathrm{~h}$ after injection, respectively. Simultaneously, at the beginning of the experiment, a control group $(n=6)$ was sacrificed to determine basal values (Table 1).

Blood samples were collected by direct puncture of the caudal vein and placed on heparin at $4{ }^{\circ} \mathrm{C}$. The blood samples were centrifuged at $500 \mathrm{~g}$ for $10 \mathrm{~min}$, in order to isolate red blood cells (RBC) from plasma (the leukocyte and upper erythrocyte layers were removed).

\subsection{Mitochondrial and cytosolic subcellular fractions isolation}

To obtain mitochondrial and cytosolic fractions, the heart was immediately removed after blood collection, weighted; and the ventricle excised. Ventricular muscle was weighted, freshly minced into small pieces, placed in ice-cold $0.5 \mathrm{M}$ sucrose containing $20 \mathrm{mM}$ Tris (tris(hydroxymethyl)aminomethane) $\mathrm{pH} 7.6,0.15 \mathrm{M} \mathrm{KCl}, 1 \mathrm{mM}$ EDTA (ethylenediaminetetraacetic acid) and $1 \mathrm{mM}$ DTT (dithiothreitol) and homogenized in an Ultra-Turrax, for three periods of $30 \mathrm{~s}$ at full speed, in $10 \mathrm{ml}$ of the same sucrose medium per gram of sample tissue. Mitochondrial and cytosolic cardiac muscle subcellular fractions were prepared according to the procedure described elsewhere [16]. Protein content was determined by Bradford method [24] using the Sigma protein dye reagent and bovine serum albumin (BSA) as protein standard.

\subsection{Subcellular vanadium distribution}

Subcellular vanadium distribution analysis of cardiac tissue (cytosolic and mitochondrial fractions) and blood (plasma and RBC) samples was performed as previous described [21]. Briefly, after drying, digestion and re-suspension, vanadium content of the residue was determined by atomic absorption spectroscopy (AAS) using a GBC Avanta atomic absorption spectrometer, equipped with a GBC GF 3000 graphite furnace system, with a GBC PAL 3000 auto sampler, working at a furnace program of $63 \mathrm{~s}$ with an argon gas flow of $3.0 \mathrm{~L} / \mathrm{min}$. The vanadium lamp was operated at $318.2 \mathrm{~nm}$, with slit width of $0.2 \mathrm{~nm}$ and the instrument was calibrated against a series of solutions containing $5,10,15$ and $20 \mathrm{ppb}$ of vanadium. Calibrating standards were obtained by successive dilutions of a Merck standard solution of vanadium $1002 \pm 2 \mathrm{mg} /$ $\mathrm{L}$. The detection and quantification limits of the instrument for these analysis conditions, determined according ISO $8466-1$, were $5 \pm 1$ and $14 \pm 3 \mathrm{ppb}$, respectively.

TORT-2, lobster hepatopancreas marine reference material for trace metals (certified vanadium content $1.64 \pm 0.19 \mathrm{mg}$ vanadium $/ \mathrm{kg}$ ), was purchased from National Research Council of Canada. Accuracy of the method was determined through analysis of the certified reference material TORT-2. Vanadium recovery ranged from $106 \%$ to $115 \%$ of the certified value. Precision was also acceptable, with $10 \%$ relative standard deviation, for this method.

\subsection{Reactive oxygen species (ROS) production assay}

The overall rate of ROS production in cardiac mitochondria was determined from the kinetics of increasing of fluorescence $\left(\lambda_{\mathrm{exc}}=495 \mathrm{~nm}, \lambda_{\mathrm{em}}=520 \mathrm{~nm}\right)$ of the probe dichlorodihydrofluorescein diacetate $\left(\mathrm{H}_{2} \mathrm{DCFDA}\right)[8,25]$. Fluorescence measurements were carried out under continuous stirring at $25^{\circ} \mathrm{C}$ with a Perkin-Elmer $650-40$ Fluorescence Spectrophotometer. The assay was performed, in a

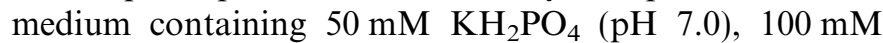
$\mathrm{KCl}$ and $2 \mathrm{ng} / \mathrm{ml} \mathrm{H}_{2}$ DCFDA and was started after sample addition.

\subsection{Superoxide dismutase and catalase activities}

Antioxidant responses in cardiac mitochondrial fraction of $S$. aurata were determined evaluating changes in antioxidant enzymes activities by UV-visible spectroscopy in a Hitachi Spectrophotometer. The catalase (CAT) activity was determined in mitochondrial fraction using the direct determination of hydrogen peroxide consumption at $240 \mathrm{~nm}$, as previously described [26], in a medium containing $50 \mathrm{mM} \mathrm{KH} \mathrm{KHO}_{4} / \mathrm{K}_{2} \mathrm{HPO}_{4} \mathrm{pH} 7.0$ and $50 \mathrm{mM} \mathrm{H}_{2} \mathrm{O}_{2}$. The superoxide dismutase (SOD) activity was evaluated in mitochondrial fraction with the xanthine oxidase-cytochrome-c method modified as described elsewhere [16] in

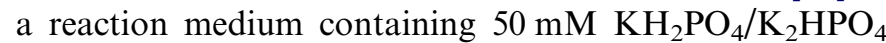
pH 7.8, $0.1 \mathrm{mM}$ EDTA, $10 \mu \mathrm{M}$ cytochrome-c, $50 \mu \mathrm{M}$ xanthine and sufficient xanthine oxidase to produce a rate of reduction of cytochrome-c at $550 \mathrm{~nm}$ of 0.025 absorbance unit per min. 


\subsection{Lipid peroxidation analysis}

The evaluation of free radical-induced damage in lipid membranes of fish heart was determined by analysis of lipid peroxidation. The evidence of lipid membrane oxidation was performed monitoring the thiobarbituric acidreactive substances (TBARS) formation in the total homogenate of heart tissue, as described elsewhere [16,27].

\subsection{Statistical analysis}

All parameters studied are present as averages and standard deviation of measurements taken from six individuals in each group. Statistical significance of the data was performed using Mann-Whitney non-parametric test. Differences from controls were considered significant at $P<0.05$.

For all parameters analysed, the groups control and placebo showed no-significant differences between them $(P>0.05)$ and therefore these two groups were considered together (Control group) for results analysis and presentation.

\section{Results and discussion}

\subsection{Characterization of vanadate solutions}

Since most of the vanadate species can be detected by

${ }^{51} \mathrm{~V}$ NMR spectroscopy, it was observed that the spectra of decavanadate stock solution, $50 \mathrm{mM}$ in total vanadium, at $\mathrm{pH}$ 7.0, contained mainly decameric species once the three signals from decameric vanadate species, ascribed to the three vanadium atoms of the decavanadate structure [28], are observed: V10A at $-517 \mathrm{ppm}, \mathrm{V} 10 \mathrm{~B}$ at $-501 \mathrm{ppm}$, $\mathrm{V} 10 \mathrm{C}$ at $-426 \mathrm{ppm}$ and a weak signal (V1) at $-562 \mathrm{ppm}$ (Fig. 1A). On the other hand, in the metavanadate stock solutions, $50 \mathrm{mM}$ total vanadium concentration, were detected monomeric (V1), dimeric (V2), tetrameric (V4) and also pentameric (V5) species, respectively, at $-561 \mathrm{ppm},-575 \mathrm{ppm},-579 \mathrm{ppm}$ and at $-587 \mathrm{ppm}$ (Fig. 1B), as described elsewhere [23].

In vanadium $(\mathrm{V})$ solutions, different oligomeric $(n=1-$ 10) vanadate species can occur simultaneously in equilibrium, e.g., monomeric (V1), dimeric (V2), tetrameric (V4) and decameric (V10) and, in same cases, with different states of protonation and conformations (Fig. 2). The predominant species are dependent of $\mathrm{pH}$, concentration and ionic strength [29]. Methods for the preparation of vanadate solutions containing only monomeric or decameric species have been developed to test the effects promoted by these species $[14,19]$. Decavanadate stock solutions contain only decameric vanadate species but when it does disintegrates the monomeric vanadate (V1) also appears in solution (Fig. 2). Metavanadate solutions contain both monovanadate (V1) and also metavanadate species such as V2 and V4 cyclic (Fig. 2). Decameric vanadate species (responsible for the orange colour of the vanadate

(B)
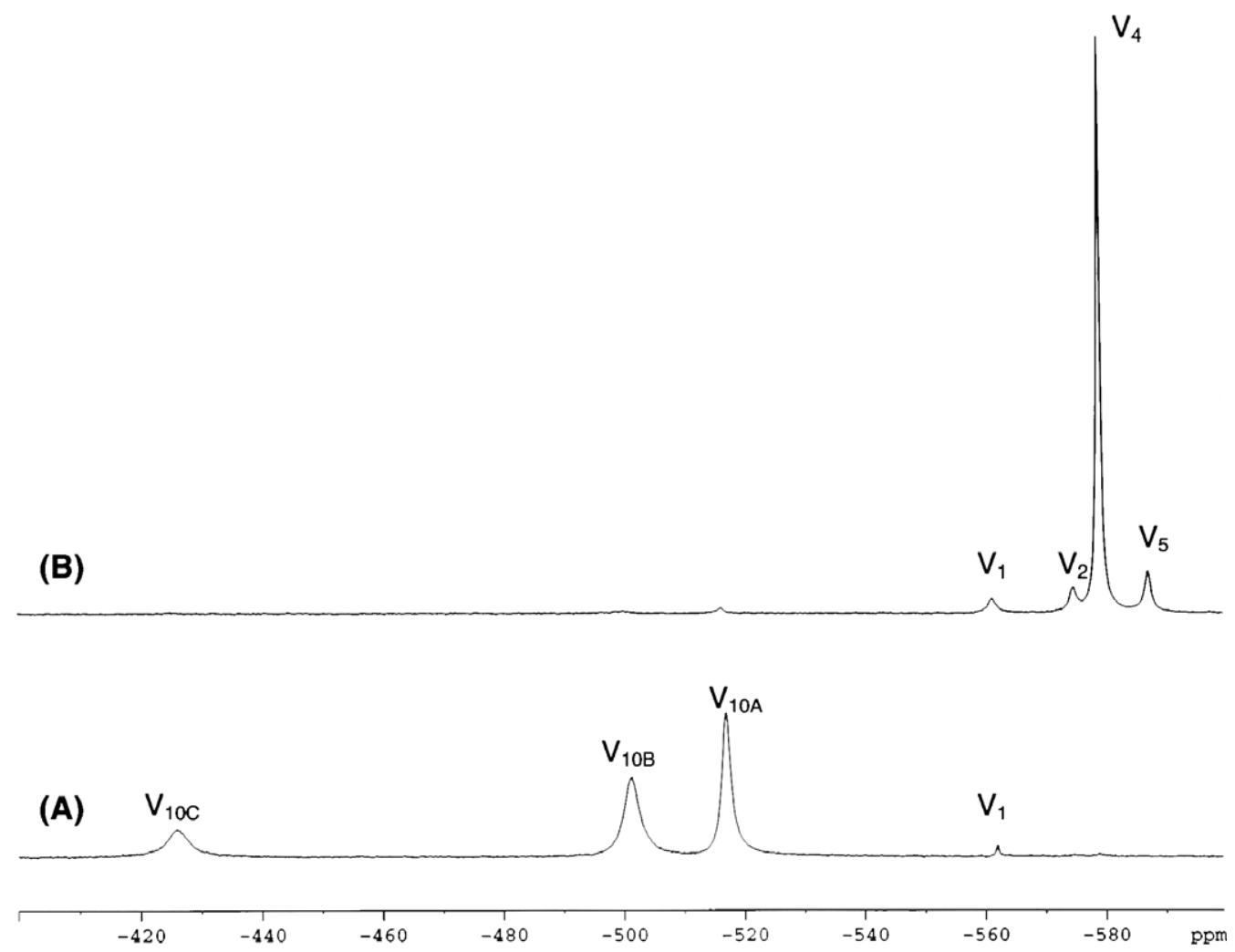

Fig. 1. 105.2 $\mathrm{MHz}^{51} \mathrm{~V}$ NMR spectra, at room temperature, of decavanadate (pH 4.0) (A) and metavanadate ( $\left.\mathrm{pH} 6.7\right)$ (B) stock solutions (50 mM total vanadium). All spectra were acquired in the presence of $10 \% \mathrm{D}_{2} \mathrm{O}$. 


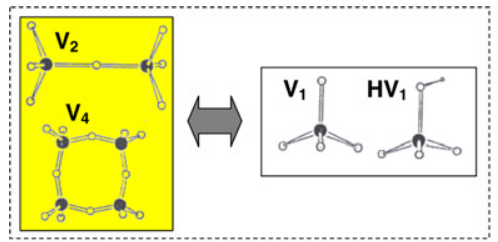

Metavanadate, $\mathrm{pH} \mathrm{6-7}$

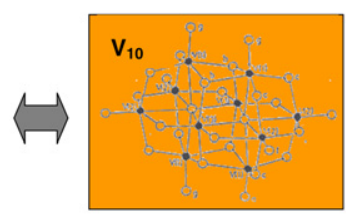

Decavanadate, $\mathrm{pH}$ 4-6
Fig. 2. Vanadate oligomers can occur simultaneously in equilibrium in aqueous solutions. Vanadate oligomers: V1, monomeric deprotonated and monoprotonated (HV1); V2, dimeric; V4, tetrameric cyclic; V10, decameric. Decavanadate (responsible for the orange colour of the vanadate solutions) could be decomposed into monomeric vanadate (colourless solutions) whereas metavanadate solutions (yellow or colourless depending upon vanadate concentration) contain labile oxovanadates in rapid equilibrium such as V1, V2 and V4 (cyclic). In the representation of some oligomeric vanadate species, vanadium atoms (black spheres), oxygen atoms (open circles) and hydrogen atoms (small open circles) are used. (Adapted from Refs. $[28,29]$.)

solutions) could be decomposed into monomeric vanadate (colourless solutions) whereas metavanadate solutions (yellow or colourless depending upon vanadate concentration) contain labile oxovanadates in rapid equilibrium such as V1, V2 and V4 (Fig. 2).

After dilution of the decavanadate solution into the injection medium $(\mathrm{NaCl} 0.9 \%)$ in the concentration normally used in the present studies ( 1 and $5 \mathrm{mM}$ in vanadium), the concentration of decameric vanadate increases linearly with total vanadate concentration whereas monomeric vanadate does not (Fig. 3A), as described recently [22]. In fact, the concentrations of each vanadate oligomer calculated by integration of the respective areas of the NMR spectra, as a function of total vanadate, exhibit different profiles according to the species. This was also observed upon dilution of the metavanadate solution into the injection medium, in the concentration range normally used in biochemical studies, different concentrations of mono-(V1); di-(V2); tetra-(V4) and pentameric-(V5) species are present, being the higher molecular vanadate oligomers favoured by increasing total vanadate concentration (Fig. 3B). For example, nominal $1 \mathrm{mM}$ metavanadate, in addition to about $500 \mu \mathrm{M}$ monomeric (V1), also contains $83 \mu \mathrm{M}$ dimeric (V2) and $84 \mu \mathrm{M}$ tetrameric (V4) species. In the presence of $5 \%$ blood plasma in the dilution medium, neither the concentration of the different vanadate species nor the ratio between vanadate oligomers in both solutions were changed. However, for $10 \%$ of blood plasma NMR signals become barely detectable, likely due to a large broadening of the peaks and pointing out to vanadate/protein interactions (not shown).

Conversely to metavanadate, the decavanadate solution is unstable in the assay medium as analysed by UV-visible spectroscopy (Fig. 4, inset graphic). In contrast to the labile oxovanadates present in the metavanadate solutions (Fig. 2), which interconvert on the time scale of milliseconds to seconds, decameric vanadate has a very slow decomposition kinetics upon dilution (Fig. 4). When decameric vanadate species present in decavanadate solutions
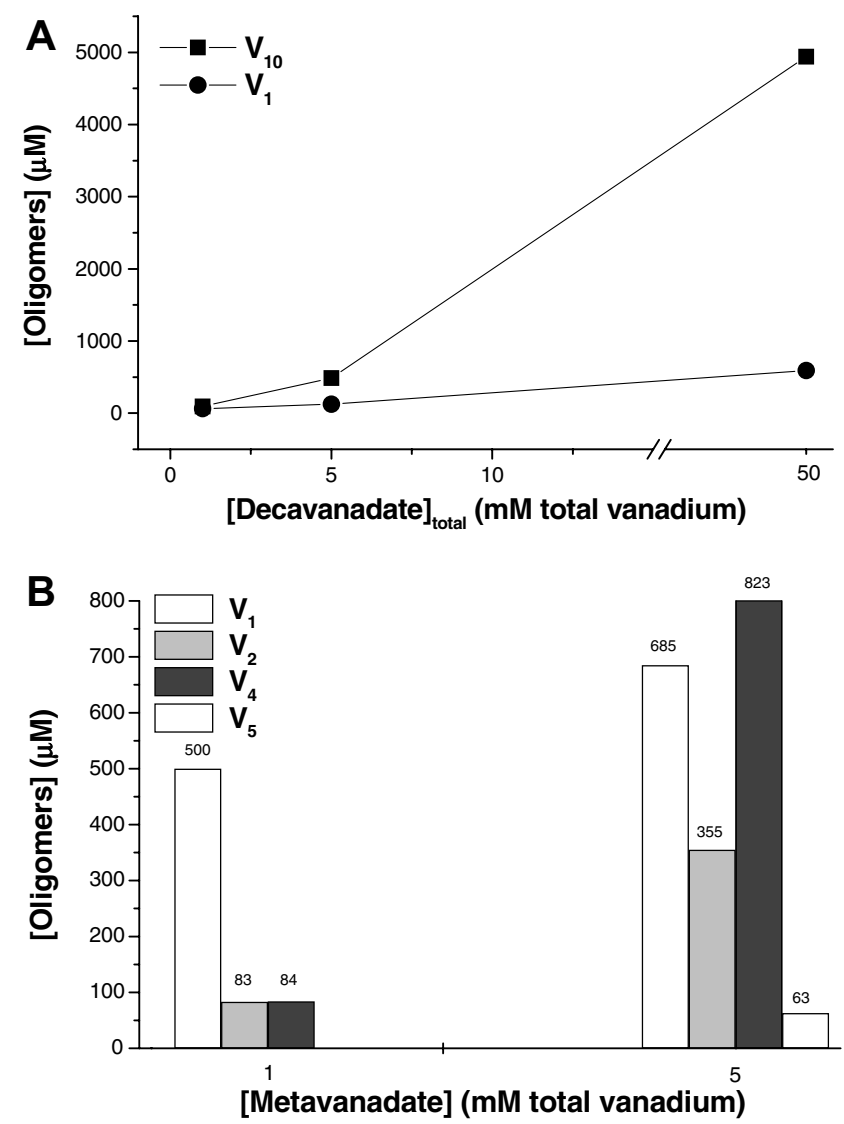

Fig. 3. Composition in vanadate oligomers of the decavanadate stock solutions ( $50 \mathrm{mM}$ total vanadium, $\mathrm{pH} 4.0$ ) and after dilution (1 and $5 \mathrm{mM}$ total vanadium) in the injection medium $(0.9 \% \mathrm{NaCl})$ (A). Vanadate oligomeric species distribution in function of total vanadium concentration in metavanadate ( $\mathrm{pH}$ 6.7) solutions, after dilution to 1 and $5 \mathrm{mM}$ (total vanadium) in the injection saline solution $(0.9 \% \mathrm{NaCl})(\mathrm{B})$.

(Fig. 2) completely decomposes into monomeric vanadate species (V1) which solutions are colourless, also the UV-visible spectra changes from the one described for the decavanadate solution to the one described for the metavanadate solution (Fig. 4, inset graphic). The kinetics of decomposition of decameric species followed by UV-visible spectroscopy, at $25^{\circ} \mathrm{C}$, in the saline solution used for in vivo administration, assessed by measurements of the absorption at $400 \mathrm{~nm}$ confirms a first-order kinetic process (Fig. 4), with an half-life time of $16 \mathrm{~h}$ (measured with $1 \mathrm{mM}$ total vanadate concentration, i.e., $100 \mu \mathrm{M}$ decameric vanadate species). After this time, the NMR spectra contain not only decameric vanadate species but also the others species present in metavanadate solutions, in agreement to described elsewhere $[14,19,23]$. Therefore, the NMR spectra of the decavanadate solution $16 \mathrm{~h}$ upon dilution, is a mixed of the spectra of Fig. 1A and B. This complex oxoanion remains relatively stable at room temperature, allowing studying its effects not only in vitro but also in vivo. Moreover, it was recently described that decameric vanadate stabilization by cytoskeletal and transmembrane proteins can account, at least in part, for decavanadate effects in biological systems [22]. 


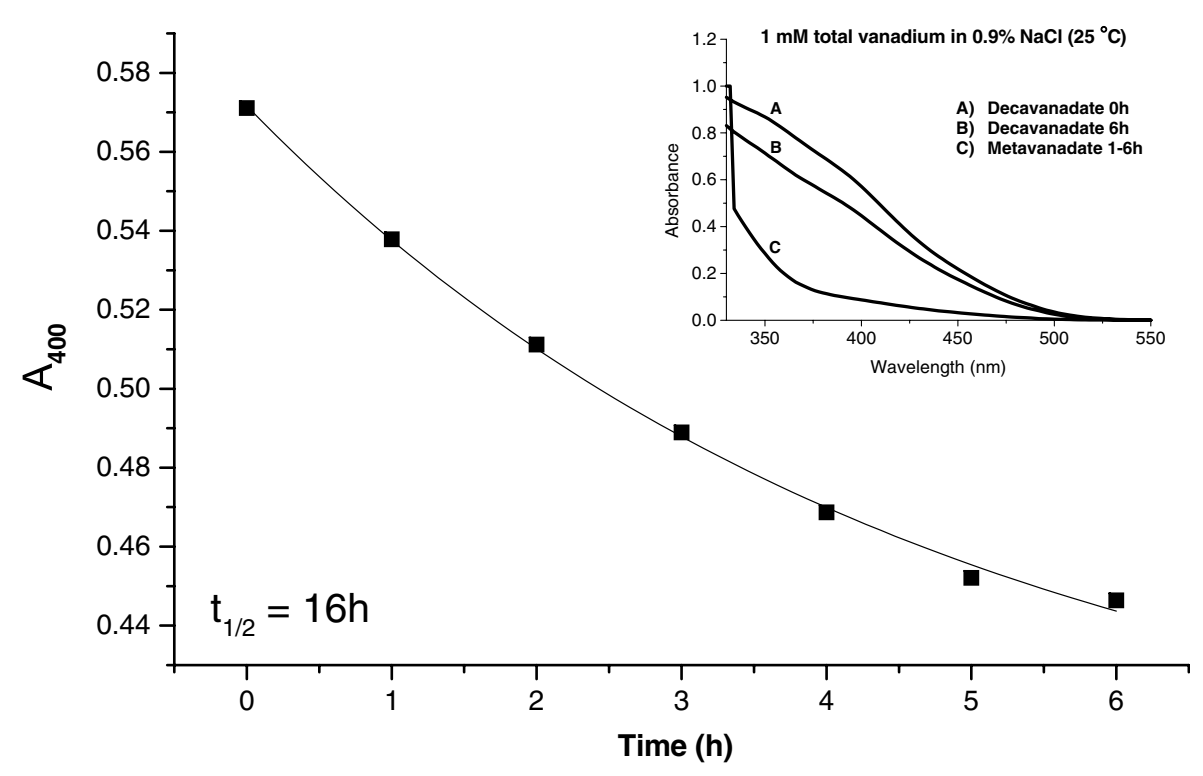

Fig. 4. Variation of the absorbance of decavanadate solution ( $1 \mathrm{mM}$ total vanadium) in $\mathrm{NaCl} 0.9 \%$, at $400 \mathrm{~nm}$, in function of time. Inset graphic: UV-visible spectra of decavanadate and metavanadate solution $\left(1 \mathrm{mM}\right.$ total vanadium), at $25^{\circ} \mathrm{C}$, in the injected dilution medium containing $0.9 \%$ $\mathrm{NaCl}$, obtained at different times $(0$ and $6 \mathrm{~h})$.

\subsection{Vanadium subcellular distribution following in vivo administration}

The amount of vanadium in Sparus aurata cardiac tissue $(46 \pm 11 \mathrm{ng} / \mathrm{g}$ dry tissue $)$ and blood $(231 \pm 45 \mathrm{ng} / \mathrm{g}$ dry tissue), are within the range of values reported for fish $[16,30,31]$. The basal vanadium content in heart is about 10 times lower than the value reported for hepatic tissue [20].

After intravenous (i.v.) administration of vanadate solutions, the highest amount of vanadium was found in blood plasma $1 \mathrm{~h}$ after exposure $(5484 \pm 1483$ and $4111 \pm 467$ $\mathrm{ng} / \mathrm{g}$ dry tissue in individuals exposed to metavanadate and decavanadate, respectively), being about 1000 -fold higher than in red blood cells (RBC) $(291 \pm 78$ and $380 \pm 135 \mathrm{ng} / \mathrm{g}$ dry tissue in individuals exposed to metavanadate and decavanadate, respectively) (Fig. 5). After 6 and $12 \mathrm{~h}$, the amount of vanadium in plasma decreases to about 4000 and $2000 \mathrm{ng} / \mathrm{g}$ dry tissue, respectively, for both vanadate solutions. In fact, it has been described that the binding of vanadium to plasma proteins is of special interest, as the vanadium binding proteins can play a role in the transport of vanadium in blood. Transferrin and albumin have been reported to be binding proteins for vanadium in human plasma [32]. In RBC, $12 \mathrm{~h}$ after vanadate i.v. administration, individuals intoxicated with metavanadate exhibits a higher concentration of vanadium (966 \pm $454 \mathrm{ng} / \mathrm{g}$ dry tissue), relatively to those injected with decavanadate ( $320 \pm 67 \mathrm{ng} / \mathrm{g}$ dry tissue) (Fig. 5).

Regarding cardiac mitochondria and cytosol, lower amounts of vanadium $(<100 \mathrm{ng} / \mathrm{g}$ dry tissue $)$ were found upon vanadate in vivo administration, not changing with exposure time in cytosol (about $50 \mathrm{ng} / \mathrm{g}$ dry tissue) for both solutions, while in mitochondria the amount of vanadium after the first hour (about $45 \mathrm{ng} / \mathrm{g}$ dry tissue) is about half of the vanadium content at 6 and $12 \mathrm{~h}$, for both solutions.
Apparently, $1 \mathrm{mM}$ decavanadate does not affect vanadium distribution at the earlier times since similar values were observed for metavanadate.

Previous works done with higher vanadate concentration $(5 \mathrm{mM})$ for the same fish species showed a tendency to vanadium accumulation in mitochondria upon decavanadate i.v. administration in comparison to cytosol, being accumulated 2-fold higher in mitochondria in the cardiac tissue and for the same exposure time [31]. On contrary, for the same concentration $(5 \mathrm{mM})$ and different mode of administration (intraperitoneal, i.p.), it was not observed the tendency of vanadium to accumulate in cardiac mitochondria upon decavanadate i.p. administration in $H$. didactylus (toadfish) [16]. Putting it all together, the distribution of vanadium in cardiac mitochondria, following decameric vanadate administration depends on total vanadium concentration and mode of administration. This finding is in agreement with the fact that vanadium subcellular distribution is dependent on the way of administration [33].

For the same mode of administration (i.v.) used in the present study but for other tissue (liver) it has also been described that vanadium accumulation is favoured in hepatic mitochondria (2-fold higher than in cytosol), $24 \mathrm{~h}$ upon $5 \mathrm{mM}$ decavanadate i.v. injection in $H$. didactylus [20]. The general tendency is that both liver and cardiac mitochondria may be a vanadium intracellular target. Apparently, for both tissues, the vanadium accumulation in mitochondria is favoured upon V10 administration.

\subsection{Lipid peroxidation}

It was observed that $1 \mathrm{~h}$ upon i.v. administration, cardiac tissue lipid peroxidation increases to the same extent for both vanadate solutions (Fig. 6). The lipid peroxidation 
Plasma

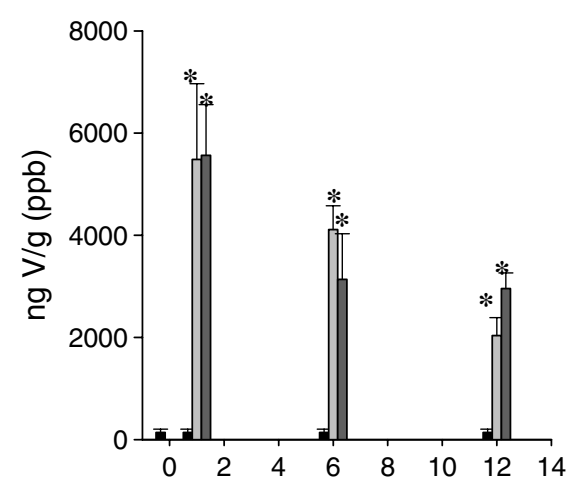

Mitochondria

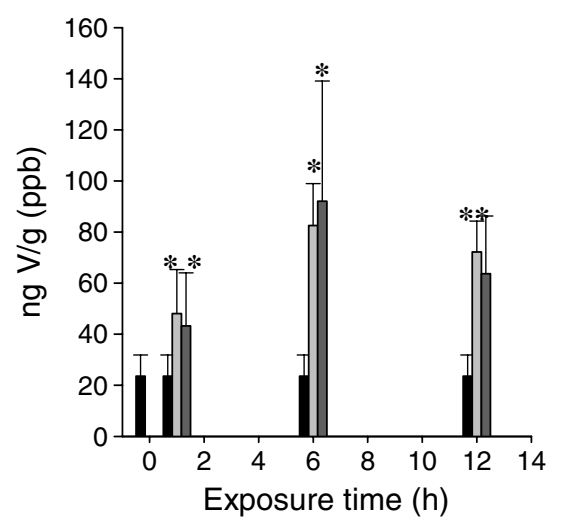

RBC

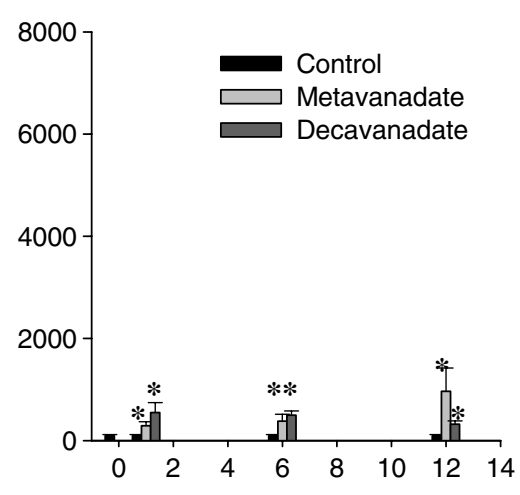

Cytosol

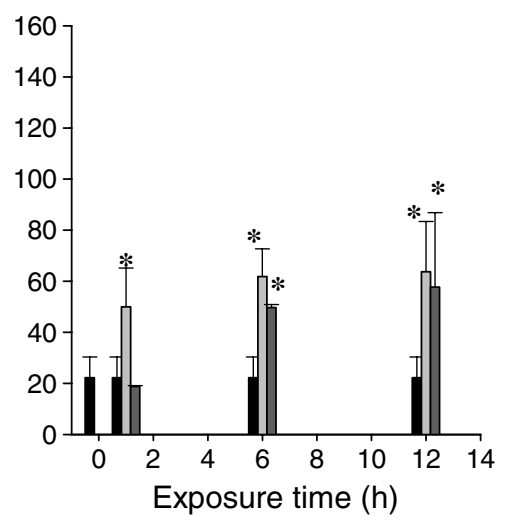

Fig. 5. Vanadium concentration, on plasma, red blood cells (RBC) cardiac tissue mitochondria and cytosol of Sparus aurata individuals $(n=4), 0,1,6$ and $12 \mathrm{~h}$ after exposure to $1 \mathrm{mM}$ (total vanadium) decavanadate and metavanadate (mean $\pm \mathrm{SD}) .{ }^{*}$ Significantly different from control $(P<0.05)$.

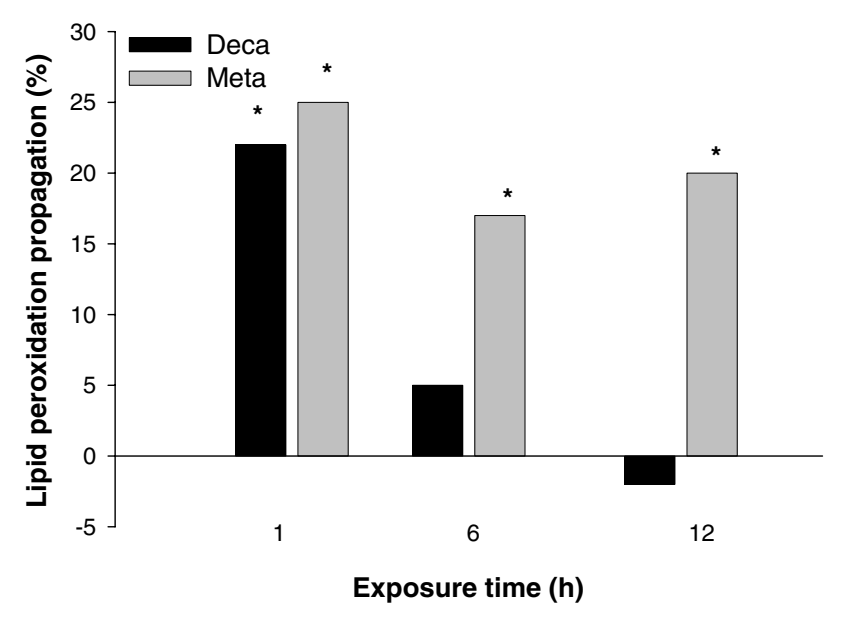

Fig. 6. Lipid peroxidation propagation variation in Sparus aurata heart. Deca and meta, refer to decavanadate and metavanadate $(1 \mathrm{mM}$ total $\mathrm{V}$, $1 \mathrm{ml} / \mathrm{kg}$ ) groups, respectively. Variation is calculated based on basal values (Table 1). Values are present as means $\pm \mathrm{SD}(n=6) .{ }^{*}$ Significantly different from control $(P<0.05)$.

products were quantified in total heart and, $1 \mathrm{~h}$ after decavanadate or metavanadate i.v. administration, both vanadate solutions increased $(P<0.05)$ the basal value $3.02 \pm 0.51 \mu \mathrm{mol} \mathrm{MDA} / \mathrm{g}$ tissue (Table 1 ) by about $20 \%$, being this effect maintained after 6 and $12 \mathrm{~h}$ only for metavanadate (Fig. 5). It has been described, for higher vanadate concentration $(5 \mathrm{mM})$, different mode of administration (i.p.), longer exposure times, different fish species (H. didactylus), but for the same tissue (heart) a significant increase $(P<0.05)$ in cardiac tissue lipid peroxidation propagation only 7 days after i.p. administration in $H$. didactylus (about $80 \%$ and $60 \%$ upon decavanadate and metavanadate, respectively) [16].

In liver tissue from a different fish species, higher vanadate concentration $(5 \mathrm{mM})$ but for the same way of administration used in the present study (i.v.) an $80 \%$ increase $(P<0.05)$ in lipid peroxidation was observed $24 \mathrm{~h}$ after i.v. administration of both vanadate solutions in $H$. didactylus [20]. In that study, decameric vanadate does not promotes significant changes $12 \mathrm{~h}$ after administration, in agreement to the results obtained in the present study, whereas metavanadate increased lipid peroxidation products by about $55 \%(P<0.05)$. However, $24 \mathrm{~h}$ after i.v. administration the lipid peroxidation value is similar to metavanadate-administered individuals $(80 \%)$ [31]. Therefore, for higher $(5 \mathrm{mM})$ decavanadate concentrations a delayed time effect in lipid peroxidation is observed for decavanadate in comparison to metavanadate.

For lower concentrations of vanadate $(1 \mathrm{mM})$ both solutions induced lipid peroxidation, but once again the effects reveal to be different and dependent on the time after 
administration (Fig. 6). It is suggested that decameric vanadate species induce peroxidation due to a different reactivity or even prevent the effects promoted by metavanadate since it does not maintain the levels exhibited by metavanadate, 6 and $12 \mathrm{~h}$ after exposure. Eventually, after administration, the total decomposition of decameric species into metavanadate would not induce the same effects observed for the latter solution. Probably, the interactions promoted by the labile oxovanadates are different from the ones induced by decameric vanadate. Moreover, by the time that V10 would totally decompose into other vanadate oligomers the targets may not be the same in order to induce the same effects as before.

\subsection{Oxidative stress markers}

The overall prooxidant activity upon vanadate exposure was determined by quantitative analysis of reactive oxygen

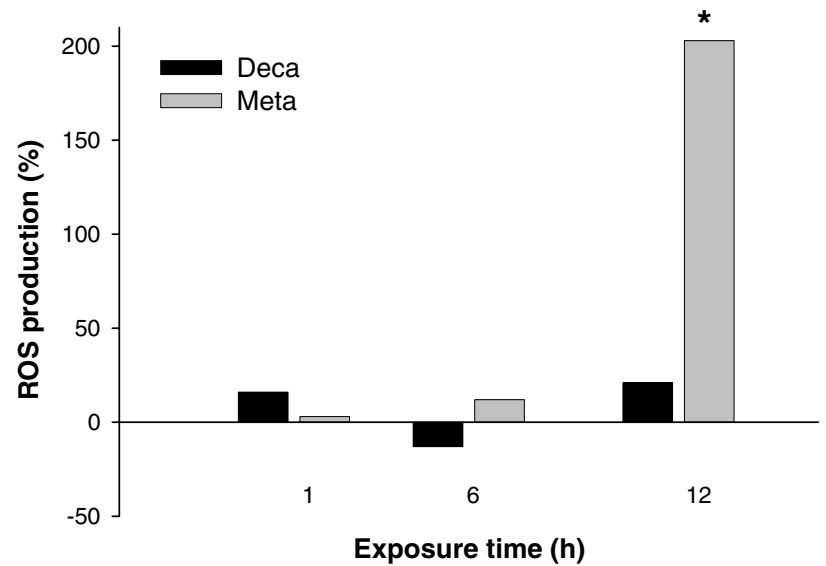

Fig. 7. Overall rate of reactive oxygen species (ROS) production variation in cardiac mitochondria of Sparus aurata. Deca and meta, refer to decavanadate and metavanadate $(1 \mathrm{mM}$ total $\mathrm{V}, 1 \mathrm{ml} / \mathrm{kg}$ ) groups, respectively. Variation is calculated based on basal values (Table 1). Values are present as means $\pm \mathrm{SD}(n=6) .{ }^{*}$ Significantly different from control $(P<0.05)$.

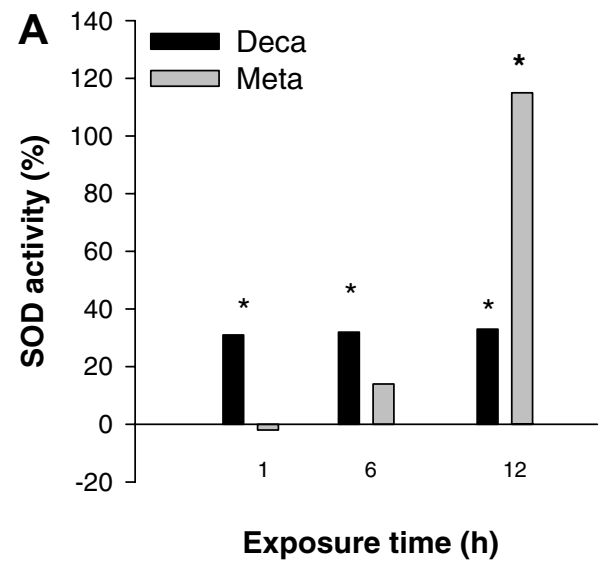

species (ROS) production and shows that, in fish heart mitochondria, only metavanadate induces a significant and delayed increase $(P<0.05)$ in ROS production (Fig. 7). The basal value for prooxidant activity in cardiac tissue $384 \pm 140$ a.u./min/mg protein (Table 1) increased above $198 \%(P<0.05), 12 \mathrm{~h}$ after metavanadate administration, whereas no significant effects were observed for decavanadate (Fig. 7). In agreement with the increase in ROS production, metavanadate induced an increase $(+115 \%)$ in mitocondrial superoxide dismutase (SOD) activity $(P<0.05), 12 \mathrm{~h}$ after exposure, while decavanadate increased about $30 \%(P<0.05)$ (at 1 and $12 \mathrm{~h}$ after i.v. administration) (Fig. 8A, Table 1). It is known that SOD activity may increase with the need of protection against oxidant agents, such as vanadate. Apparently, only metavanadate act as a prooxidant since decavanadate does not induce the same overall response probably due to different reactivities that can result from different mechanisms. Concerning mitochondrial catalase (CAT) activity, the basal CAT activity in mitochondria $(1.63 \pm$ $0.51 \mathrm{nmol} / \mathrm{min} / \mathrm{mg}$ protein) (Table 1) decrease by $-55 \%$ $(P<0.05) 12 \mathrm{~h}$ after decavanadate exposure, whereas metavanadate induced no significant effects (Fig. 8B). Putting it all together, $1 \mathrm{mM}$ decavanadate in vivo administration differs from metavanadate in not inducing cardiac mitochondrial ROS production and SOD activity besides decreasing catalase activity. Therefore, more pronounced prooxidant effects occur in cardiac mitochondria following i.v. metavanadate exposure whereas decavanadate administration seems to prevent this effect, probably by binding to target proteins preventing its decomposition to vanadate that induces the producing of reactive oxygen species or due to different reactivities.

The decrease on the activity of CAT by V10, is in agreement to previous results from this laboratory, as we reported that decavanadate induce a decrease in cardiac mitochondrial catalase activity $(-60 \%), 7$ days following $5 \mathrm{mM}$ decavanadate i.p. administration in $H$. didactylus [16]. Reduction of catalase activity was also described in

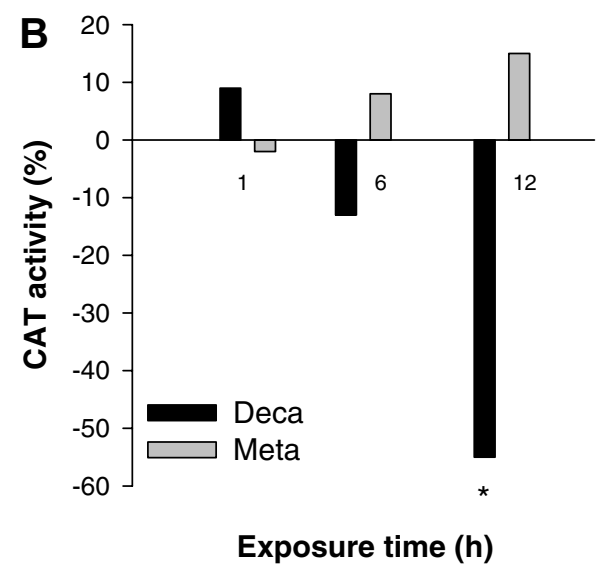

Fig. 8. Superoxide dismutase (SOD) (A) and catalase (CAT) (B) activity variation in mitochondria from Sparus aurata cardiac tissue. Deca and meta, refer to decavanadate and metavanadate $(1 \mathrm{mM}$ total $\mathrm{V}, 1 \mathrm{ml} / \mathrm{kg}$ ) groups, respectively. Variation is calculated based on basal values (Table 1$)$. Values are present as means $\pm \mathrm{SD}(n=6) .{ }^{*}$ Significantly different from control $(P<0.05)$. 
fish exposure to cadmium [34] and silver [35]. In liver, it was described that decavanadate and metavanadate administration clearly induce different changes in oxidative stress markers [20]. On the other hand, a previous study [16] concluded that there are not any significant changes in mitochondrial SOD activity in $H$. didactylus, 1 and 7 days following i.p. exposure to $5 \mathrm{mM}$ decavanadate or metavanadate. Therefore, the antioxidants responses induced by vanadate may depend on the total vanadium concentration administered, on the way of exposure and/or vary between fish species, besides the vanadate species composition of vanadate solutions.

\subsection{Concluding remarks}

In contrast to metavanadate solutions containing several labile oxovanadates species in equilibrium, decavanadate solutions contain decameric vanadate species, whose dissociation is slow enough to study its in vivo effects. The piscine models seem to be adequate to study the effects of the administration of decavanadate in antioxidant stress markers, lipid peroxidation and vanadium subcellular distribution, not only due to the physiological temperature but also due to their sensitive to metal toxicity.

At early stage of exposure (1, 6 and $12 \mathrm{~h}$ ) and at lower vanadium concentration $(1 \mathrm{mM})$, decavanadate has a different pattern of lipid peroxidation and it does not induce the increase of ROS production and SOD activity, on the contrary it decreases catalase activity, although does not affect vanadium distribution in comparison to metavanadate. It is proposed that the administration of decameric vanadate clearly induces different biological responses than other labile oxovanadates probably due to different reactivities that can result from different mechanisms, pointing out the importance of taking in account the V10 species in the evaluation of vanadate effects.

\section{Acknowledgements}

This work has been supported by Joint Spanish-Portuguese Grant HP2004-0080 (to C.G.-M. and M.A.), by POCTI program funded through FEDER for the research project POCTI/38191/QUI/2001 (to M.A.), by Grant 3PR05A078 of the Junta de Extremadura (to C.G.-M.) and CRUP project E-106/05. SSSoares was supported by a PhD grant [SFRH/BD/8615/2002] from the Portuguese Foundation for Science and Technology (FCT). The authors gratefully acknowledge the Dr. Maria do Rosário Caras Altas the excellent technical assistance provided at the Laboratório de Ressonância Magnética Nuclear, Departamento de Química, Universidade Nova de Lisboa.

\section{References}

[1] A.M. Ghe, C. Stefanelli, P. Tsintiki, G. Veschi, Talanta 32 (1985) 359-362.
[2] P. Kalyani, S. Vijaya, T. Ramasarma, Mol. Cell. Biochem. 111 (1992) 33-40.

[3] E.G. Ferrer, P.A.M. Williams, E.J. Baran, J. Inorg. Biochem. 50 (1993) 253-262.

[4] S.J. Stohs, D. Bagchi, Free Radic. Biol. Med. 18 (1995) 321-336.

[5] S.J. Shi, H.G. Preuss, D.R. Abernethy, X. Li, S.T. Jarrell, N.S. Andrawis, J. Hypertens. 15 (1997) 857-862.

[6] J.Z. Byczkowski, A.P. Kulkarni, in: J.O. Nriagu (Ed.), Vanadium in the Environment. Part 2. Health Effects, John Wiley and Sons, New York, 1998, pp. 135-157.

[7] L. Capella, M. Gefé, E. Silva, E. Affonso-Mitidieri, A. Lopes, V. Rumjanek, M. Capella, Arch. Biochem. Biophys. 406 (2002) 65-72.

[8] Z. Zhang, S. Leonard, C. Huang, V. Vallyathan, V. Castranova, X. Shi, Free Radic. Biol. Med. 34 (2003) 1333-1342.

[9] I.S. Jamall, M. Naik, J.J. Sprowls, L.D. Trombetta, J. Appl. Toxicol. 9 (1989) 339-345.

[10] L. Tort, L. Madsen, Comp. Biochem. Physiol. C 99 (1991) 353-358.

[11] S. Sarkar, P. Yadav, R. Trivedi, A.K. Bansal, D. Bhatnagar, J. Trace Elem. Med. Biol. 9 (1995) 144-149.

[12] D.A. Limaye, Z.A. Shaikh, Toxicol. Appl. Pharmacol. 154 (1999) 5966.

[13] P.J. Stankiewicz, A.S. Tracey, D.C. Crans, in: H. Sigel, A. Sigel (Eds.), Metal Ions in Biological Systems: Vanadium and its Role in Life, Marcel Dekker, New York, 1995, pp. 287-324.

[14] M. Aureliano, V.M.C. Madeira, Adv. Environ. Sci. Tecnol. 30 (1998) 333-357.

[15] T. Tiago, M. Aureliano, C. Gutiérrez-Merino, Biochemistry 43 (2004) 5551-5561.

[16] M. Aureliano, N. Joaquim, A. Sousa, H. Martins, J.M. Coucelo, J. Inorg. Biochem. 90 (2002) 159-165.

[17] S.S. Soares, M. Aureliano, N. Joaquim, J.M. Coucelo, J. Inorg. Biochem. 94 (2003) 285-290.

[18] G. Borges, P. Mendonça, N. Joaquim, M. Aureliano, J.M. Coucelo, Arch. Environ. Contam. Toxicol. 45 (2003) 415-422.

[19] M. Aureliano, R.M.C. Gândara, J. Inorg. Biochem. 99 (2005) 979 985.

[20] R.M.C. Gândara, S.S. Soares, H. Martins, C. Gutiérrez-Merino, M. Aureliano, J. Inorg. Biochem. 99 (2005) 1238-1244.

[21] S.S. Soares, H. Martins, M. Aureliano, Arch. Environ. Contam. Toxicol. 50 (2006) 60-64.

[22] S. Ramos, M. Manuel, T. Tiago, R.M.C. Gândara, R.O. Duarte, J.J.G. Moura, C. Gutiérrez-Merino, M. Aureliano, J. Inorg. Biochem., in press.

[23] M. Aureliano, V.M. Madeira, Biochem. Biophys. Res. Commun. 205 (1994) 161-167.

[24] M.M. Bradford, Anal. Biochem. 72 (1967) 248-254.

[25] F.J. Martín-Romero, E. García-Martín, C. Gutiérrez-Merino, J. Neurochem. 82 (2002) 705-715.

[26] A. Clairborne, in: R.A. Greenwald (Ed.), Handbook of Methods for Oxygen Radical Research, CRC Press, Boca Raton, Florida, 1985, pp. 283-284.

[27] D. Wills, in: K. Snell, B. Mullock (Eds.), Biochemical Toxicology: A Practical Approach (pp), IRL Press, Oxford, 1987, pp. 127-152.

[28] O.W. Howarth, M. Jarrold, J. Chem. Soc. Dalton 22 (1978) 453-485.

[29] A. Amado, M. Aureliano, P.J. Ribeiro-Claro, J. Teixeira-Dias, J. Raman Spect. 24 (1993) 669-703.

[30] P. Miramand, S. Fowler, in: J.O. Nriagu (Ed.), Vanadium in the Environment. Part 2. Health Effects, John Wiley and Sons, New York, 1998, pp. 167-197.

[31] I. Al-Saleh, N. Shinwari, Chemosphere 48 (2002) 749-755.

[32] N. Chasteen, Struct. Bond. 53 (1983) 105-138.

[33] H. Zaporowska, A. Scibior, in: J.O. Nriagu (Ed.), Vanadium in the Environment. Part 2. Health Effects, John Wiley and Sons, New York, 1998, pp. 135-157.

[34] R.J. Pruell, F.R. Engelhardt, Mar. Environ. Res. 3 (1980) 101-111.

[35] G. Atli, Ö. Alptekin, S. Tükel, M. Canli, Comp. Biochem. Physiol. C 143 (2006) 218-224. 